\title{
Aripiprazole for the treatment of psychotic symptoms in patients with dementia with Lewy bodies: a case series
}

This article was published in the following Dove Medical Press journal: Neuropsychiatric Disease and Treatment

\author{
Yuka Sugawara Kikuchi \\ Tetsuo Shimizu \\ Department of Neuropsychiatry, \\ Akita University Graduate School of \\ Medicine, Akita 0 l0-8543, Japan
}

Purpose: The core features of dementia with Lewy bodies (DLB) are cognitive fluctuations, visual hallucinations, and parkinsonian symptoms. Although there have been several reports on the efficacy of treatments for psychotic symptoms in patients with DLB, little is known regarding the treatment effects of aripiprazole. The aim of this study was to evaluate the efficacy and safety of aripiprazole for the treatment of psychotic symptoms in patients with DLB.

Patients and methods: We employed a 10-week, open-label study design with 11 patients who met the criteria for DLB. The patients had previously experienced persistent or intermittent delusions, hallucinations, or both for at least 1 month. Aripiprazole was initiated at a low dose (3 or $6 \mathrm{mg} /$ day) and titrated to higher doses at 2-week intervals or more rapidly, as needed. The Neuropsychiatric Inventory (NPI), Brief Psychiatric Rating Scale (BPRS), and Clinical Global Impression-Severity (CGI-S) were administered at baseline and 1, 2, 4, 8, and 10 weeks later. The Simpson-Angus Scale (SAS), Clinical Dementia Rating (CDR), and Mini-Mental State Examination (MMSE) Scale were evaluated at baseline and at week 10. The NPI, CGI-S, and BPRS scores were compared between the baseline and each assessment point and between each assessment point and the one before assessment point. The SAS, CDR, and MMSE scores were compared between the baseline and the end point. Results: The mean NPI and BPRS scores improved until the fourth week; they significantly decreased at each assessment point compared to the previous one. Afterward, improvements slowed and continued without significant decrease. The median SAS scores significantly decreased at the end point compared to the baseline $(P<0.05)$. The median MMSE score was higher at the end point than at the baseline $(P<0.05)$.

Conclusion: This study showed that aripiprazole may be effective and well tolerated for the treatment of psychotic symptoms in patients with DLB.

Keywords: aripiprazole, Lewy bodies, dementia, psychotic symptoms

\section{Introduction}

Dementia with Lewy bodies (DLB) is considered the second most common form of dementia after Alzheimer's disease (AD). ${ }^{1}$ Aarsland et $\mathrm{al}^{2}$ reported similar results of the proportion of DLB in a cohort study (AD, 65\%; DLB, 20\%). DLB is often misdiagnosed as AD or parkinsonism-related dementia. The core clinical features of DLB include neuropsychiatric and parkinsonian motor symptoms as well as cognitive impairment characterized by deficits in attention, executive function, and visual perception. ${ }^{1}$ Fluctuating cognition, hallucinations, and delusions are major sources of difficulty and distress for both patients and caregivers. ${ }^{3}$

Aripiprazole is a second-generation atypical antipsychotic which has been approved for schizophrenia, mania, or mixed episodes associated with bipolar I disorder and
Correspondence: Yuka Sugawara Kikuchi Department of Neuropsychiatry, Akita University Graduate School of Medicine I-I-I Hondo, Akita 0 I0-8543, Japan

$\mathrm{Tel}+8 \mid 188846122$

Fax +8I I8 8846445

Email yuka@med.akita-u.ac.jp 
as an adjunctive treatment for major depressive disorder. ${ }^{4}$ The proposed mechanism of action for its efficacy is a combination of partial agonistic activity at D2 and 5-HT1A receptors and antagonistic activity at 5-HT2A receptors. ${ }^{5}$ Furthermore, aripiprazole is presumed to have a weight gain, sedation, elevated serum prolactin levels, or prolongation of the heart rate-corrected QT interval on electrocardiography. ${ }^{6}$ The QT interval represents the time from the onset of ventricular depolarization to completion of repolarization, and prolongation has been associated with ventricular arrhythmias that may trigger ventricular fibrillation and sudden death.

Although there have been several reports on the efficacy of treatments for psychotic symptoms in patients with DLB, little is known regarding the treatment effects of aripiprazole. In this article, we describe our retrospective, open-label experience with aripiprazole for the treatment of psychotic symptoms in patients with DLB.

\section{Patients and methods}

We recruited consecutive nonselected patients from our institution. Eleven patients who met the consensus diagnostic criteria for DLB participated in this study, ${ }^{1}$ including two men and nine women. Their average age was 76 years (range, 65-84 years). The patients had experienced persistent or intermittent delusions, hallucinations, or both for at least 1 month before enrolment in the study. Patients were accompanied by caregivers who routinely remained with them, provided information on this study, and assisted with treatment compliance. Patients who improved with environmental coordination and/or dementia medications and those who had schizophrenia, or brain damage, or a score of 25 or more on the Mini-Mental State Examination (MMSE) Scale were excluded. This study was approved by the institutional review board and ethical committee of Akita University Graduate School of Medicine. All patients or their families provided written informed consent before entering this study. This study was conducted according to the principles expressed in the Declaration of Helsinki.

Aripiprazole was initiated at a low dose (3 or $6 \mathrm{mg} /$ day) and titrated to higher doses at 2-week intervals or more rapidly, based on the investigator's judgment, if the patient showed insufficient clinical response. Reductions from higher doses were permitted for tolerability (Table 1). The maximum dose of aripiprazole was $30 \mathrm{mg} /$ day, as defined in Japan. The patients' use of medications prior to aripiprazole administration was not changed throughout this trial.

The patients' clinical status was assessed at baseline and 2, 4, 8, and 10 weeks later using the Neuropsychiatric Inventory (NPI), Clinical Global Impression-Severity (CGI-S), and Brief Psychiatric Rating Scale (BPRS) to measure psychotic symptoms. The Simpson-Angus Scale (SAS) was used to measure parkinsonian symptoms, and the Clinical Dementia Rating (CDR) and MMSE scores were used to evaluate cognitive function. The NPI, CGI-S, and BPRS scores were compared between baseline and each assessment point and between each assessment point and the previous one with Tukey's test. The SAS, CDR, and MMSE scores were compared between the baseline and the end point with a Wilcoxon signed-rank test. Statistical analyses were performed using the Statcel3 software (OMS Publishing, Saitama, Japan) with the significance level at $5 \%$.

\section{Results}

Patient characteristics are outlined in Table 2. Nine of the 11 patients $(81.8 \%$ ) completed the 10 -week study. Reasons for withdrawal included hypersalivation (case 5) and drug

Table I Patients' aripiprazole doses

\begin{tabular}{|c|c|c|c|c|c|c|}
\hline \multirow[t]{2}{*}{ Case } & \multicolumn{6}{|c|}{ Dose of aripiprazole (mg/day) } \\
\hline & Baseline & I week & 2 weeks & 4 weeks & 8 weeks & 10 weeks \\
\hline 1 & 6 & 6 & 12 & 12 & 12 & 12 \\
\hline 2 & 3 & 3 & 6 & 9 & 12 & 12 \\
\hline 3 & 3 & 3 & 6 & 6 & 9 & 9 \\
\hline 4 & 3 & 3 & 6 & 9 & 12 & 12 \\
\hline 5 & 3 & 3 & 6 & - & - & - \\
\hline 6 & 3 & 3 & 6 & 6 & 6 & 6 \\
\hline 7 & 3 & 3 & 6 & 6 & 6 & 6 \\
\hline 8 & 6 & 6 & 12 & 12 & 12 & 12 \\
\hline 9 & 6 & 6 & 12 & 12 & 12 & 12 \\
\hline 10 & 3 & 3 & - & - & - & - \\
\hline II & 6 & 6 & 12 & 12 & 12 & 12 \\
\hline Mean & 4.1 & 4.1 & 8.4 & 9.3 & 10.3 & 10.3 \\
\hline
\end{tabular}


Table 2 Patient characteristics

\begin{tabular}{|l|l|l|l|l|l|l|l|}
\hline Case & Sex & $\begin{array}{l}\text { Age } \\
\text { (years) }\end{array}$ & $\begin{array}{l}\text { Category } \\
\text { of DLB }\end{array}$ & Stage & $\begin{array}{l}\text { Concomitant } \\
\text { medication }\end{array}$ & $\begin{array}{l}\text { Complication of } \\
\text { mental illness }\end{array}$ & $\begin{array}{l}\text { Inpatient/ } \\
\text { outpatient }\end{array}$ \\
\hline I & F & 78 & Probable & Moderate & Valproic acid & MDI & Inpatient \\
\hline 2 & F & 65 & Probable & Severe & Clonazepam & RBD & Outpatient \\
\hline 3 & F & 84 & Probable & Moderate & Benzodiazepine & D & Outpatient \\
\hline 4 & M & 83 & Probable & Moderate & Clonazepam & RBD & Outpatient \\
\hline 5 & F & 83 & Probable & Moderate & - & MDI & Outpatient \\
\hline 6 & F & 75 & Probable & Moderate & - & - & Outpatient \\
\hline 7 & F & 78 & Probable & Severe & - & - & Outpatient \\
\hline 8 & M & 73 & Probable & Moderate & Maprotiline & D & Inpatient \\
\hline 9 & F & 72 & Probable & Moderate & Benzodiazepine & MDI & Inpatient \\
\hline I0 & F & 75 & Probable & Severe & - & - & MDI \\
\hline II & F & 74 & Probable & Moderate & - & Inpatient \\
\hline
\end{tabular}

Note: Stage, based on baseline MMSE scale (severe, 0-9; moderate, 10-19; mild, 20-23).

Abbreviations: D, depression; DLB, dementia with Lewy bodies; F, female; M, male; MDI, manic-depressive illness; MMSE, Mini-mental State Examination; RBD, rapid eye movement sleep behavior disorder.

denial due to lack of appetite (case 10). The mean dose of aripiprazole at the end point was $10.3 \mathrm{mg} /$ day (range, 6-12 mg/day). There were no significant differences in the mean NPI, BPRS, CGI-S, and the median SAS, CDR, and MMSE scores between outpatients and inpatients at baseline. The mean NPI and BPRS scores decreased until the fourth week after the initiation of the aripiprazole treatment. The mean scores of NPI and BPRS significantly decreased at each assessment point compared to the previous one $(P<0.01)$. After 4 weeks, improvements slowed and continued without a significant decrease (Figure 1). The mean CGI-S score significantly decreased until the eighth week $(P<0.01)$. The mean scores of CGI-S significantly decreased at each assessment point compared to the previous one $(P<0.01)$.
The median SAS and MMSE scores significantly improved at the study end point compared to the baseline $(P<0.05)$. The median CDR score did not significantly decrease (Table 3 ).

\section{Discussion}

In the present study, we found that aripiprazole reduced psychotic symptoms in patients with DLB. Although Mintzer et $\mathrm{al}^{7}$ reported that aripiprazole, at $10 \mathrm{mg} / \mathrm{day}$ and $15 \mathrm{mg} / \mathrm{day}$, was effective in reducing the symptoms of psychosis in patients with $\mathrm{AD}$, to the best of our knowledge, this is the first report of aripiprazole's effectiveness in reducing psychotic symptoms in DLB. However, numerous other medications have been studied with regard to DLB. Lee et $\mathrm{al}^{8}$ and Allen et $\mathrm{al}^{9}$ reported a favorable response to treatment

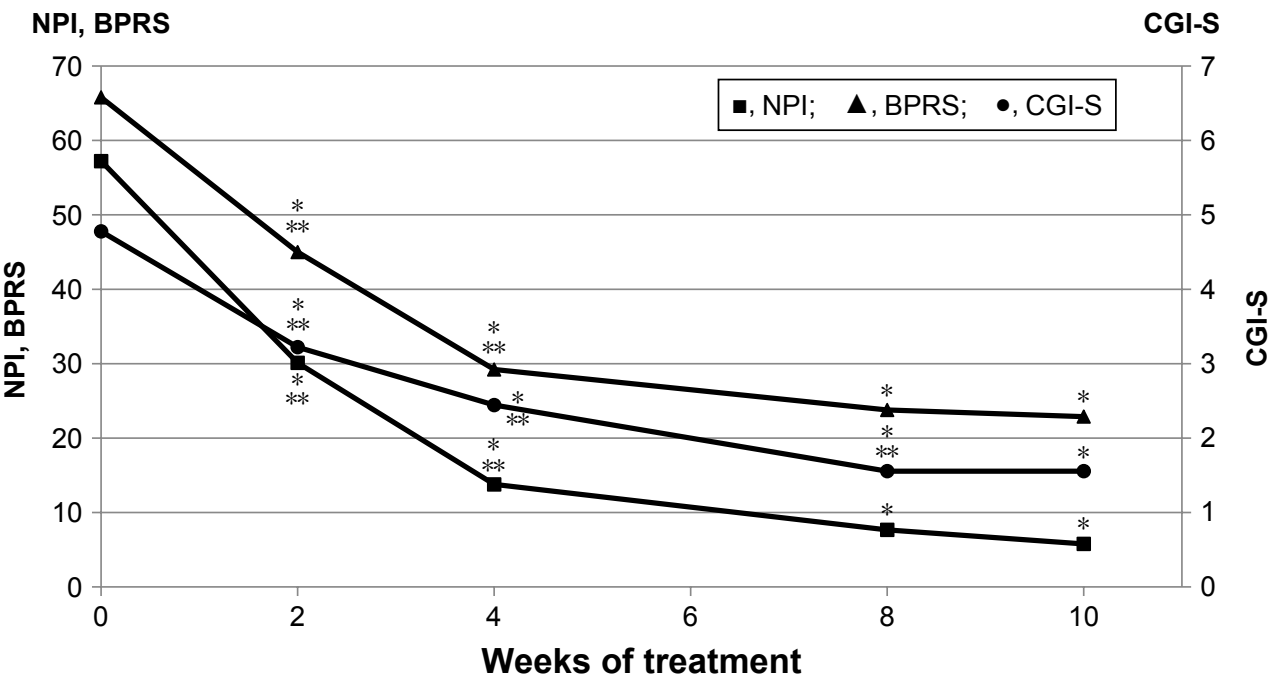

Figure I Mean NPI, BPRS, and CGI-S scores of the patients who completed the study.

Notes: *Significantly decreased compared to baseline $(P<0.0 \mathrm{I})$. **Significantly decreased compared to previous assessment point $(P<0.0 \mathrm{I})$.

Abbreviations: BPRS, Brief Psychiatric Rating Scale; CGI-S, Clinical Global Impression-Severity; NPI, Neuropsychiatric Inventory. 
Table 3 Median SAS, CDR, and MMSE scores (range) of the patients who completed the study

\begin{tabular}{|l|l|l|l|}
\hline Measure & Baseline & 10 weeks & $P$-value \\
\hline SAS $^{a}$ & $9(4-14)$ & $6(4-9)$ & $<0.05$ \\
\hline CDR $^{a}$ & $2(1-3)$ & $1(1-2)$ & NS \\
\hline MMSE $^{a}$ & $15(9-19)$ & $17(12-2 I)$ & $<0.05$ \\
\hline
\end{tabular}

Note: ${ }^{a}$ Wilcoxon signed-rank test.

Abbreviations: CDR, Clinical Dementia Rating; MMSE, Mini-mental State Examination; NS, not significant; SAS, Simpson-Angus Scale.

with $0.5-5 \mathrm{mg}$ risperidone per day for the psychotic and behavioral symptoms of DLB. Takahashi et al ${ }^{10}$ described that quetiapine was effective for coping with psychotic symptoms and aggressive behaviors in patients with DLB. Some reports have suggested that donepezil is effective for the treatment of psychotic and behavioral symptoms in DLB., ${ }^{3,11}$ In the present study, the mean NPI and BPRS scores significantly decreased until the fourth week after the initiation of the aripiprazole treatment (mean dose, $9.3 \mathrm{mg} /$ day), after which the psychotic symptoms stabilized. The mean CGI-S score significantly decreased until the eighth week, after which the psychotic symptoms stabilized. These results indicate that improvement was shown in the initial 4-week period, after which the psychotic symptoms stabilized.

The most common side effects reported with aripiprazole were headache, insomnia, agitation, and anxiety. Marder et $\mathrm{al}^{12}$ reported that discontinuation due to side effects occurred at an incidence rate of $7 \%$. We had to discontinue aripiprazole treatment in 2 of our 11 patients because of hypersalivation (case 5) and drug denial and a lack of appetite (case 10). Both these reasons for the withdrawal of the aripiprazole treatment were mild in severity. In terms of motoric improvements, there was no significant median baseline end point change in the SAS after aripiprazole treatment. Aripiprazole has a high 5HT2/D2 ratio and may therefore carry a low risk of extrapyramidal syndrome (EPS). ${ }^{13}$ This has been concluded based on several reports that have shown that the incidence of EPS-related side effects is low in aripiprazole treatments. ${ }^{11,14,15}$ In our study, aripiprazole was found to be safe and well tolerated for the treatment of patients with DLB.

In the study of aripiprazole in $\mathrm{AD}$ by De Deyn et al, ${ }^{14}$ only minimal mean changes in the MMSE score were observed from the baseline to the end point (aripiprazole, -0.81 ; placebo, $-0.53 ; P<0.001)$. Other AD studies have shown that the aripiprazole and placebo groups did not significantly differ in mean change in MMSE score at the end point. ${ }^{11,15}$ In contrast, several observational studies have shown that aripiprazole improves cognitive impairment in patients with schizophrenia. ${ }^{16-19}$ In the present study, we demonstrated a significantly higher median MMSE score at the end point of the study compared to the baseline. This finding suggests that aripiprazole improved cognitive impairment in patients with DLB.

Our study was open label, and several factors disallow drawing definitive conclusions based on the present findings. The starting dose of aripiprazole and the titration schedule were not standardized. Although we recruited from consecutive patients, participants in this study consisted of predominantly women. It might be raise referral bias. The small sample size and lack of control group were also limitations of this study.

\section{Conclusion}

Aripiprazole may be effective and well tolerated for the treatment of psychotic symptoms in patients of DLB, but further placebo-controlled double-blind trials, with larger number of patients, are needed to confirm this observation.

\section{Acknowledgments}

The abstract of this paper was presented at the 24th European Congress of Psychiatry as a poster presentation with interim findings. The poster's abstract was published in "Poster Abstracts" in European Psychiatry (http://www.jscnp.org/ en/abstracts/19/19th Abstracts.pdf).

\section{Author contributions}

YSK contributed to study design, data collection, and analysis and interpretation of the data and wrote the manuscript. TS contributed to study design and provided comments on the manuscript. All authors contributed to data analysis, drafting and revising the article, gave final approval of the version to be published, and agree to be accountable for all aspects of the work.

\section{Disclosure}

The authors report no conflicts of interest in this work.

\section{References}

1. Mckeith IG, Galasko D, Kosaka K, et al. Consensus guidelines for the clinical and pathologic diagnosis of dementia with Lewy bodies (DLB): report of the Consortium on DLB International workshop. Neurology. 1996;47(5):1113-1124.

2. Aarsland D, Rongve A, Nore SP, et al. Frequency and case identification of dementia with Lewy bodies using the revised consensus criteria. Dement Geriatr Cogn Disord. 2008;26(5):445-452.

3. Mori E, Ikeda M, Kosaka KS; Investigators D-DLBS, DonepezilDLB Study Investigators. Donepezil for dementia with Lewy bodies: a randomized, placebo-controlled trial. Ann Neurol. 2012;72(1): $41-52$.

4. Kohen I, Lester PE, Lam S. Antipsychotic treatments for the elderly: efficacy and safety of aripiprazole. Neuropsychiatr Dis Treat. 2010;6: $47-58$.

5. Deleon A, Patel NC, Crismon ML. Aripiprazole: a comprehensive review of its pharmacology, clinical efficacy, and tolerability. Clin Ther. 2004;26(5):649-666. 
6. Burris KD, Molski TF, Xu C, et al. Aripiprazole, a novel antipsychotic, is a high-affinity partial agonist at human dopamine D2 receptors. J Pharmacol Exp Ther. 2002;302(1):381-389.

7. Mintzer JE, Tune LE, Breder CD, et al. Aripiprazole for the treatment of psychoses in institutionalized patients with Alzheimer dementia: a multicenter, randomized, double-blind, placebo-controlled assessment of three fixed doses. Am J Geriatr Psychiatry. 2007;15(11):918-931.

8. Lee H, Cooney JM, Lawlor BA. The use of risperidone, an atypical neuroleptic, in Lewy body disease. Int J Geriatr Psychiatry. 1994;9(5): 415-417.

9. Allen RL, Walker Z, D'Ath PJ, Katona CL. Risperidone for psychotic and behavioural symptoms in Lewy body dementia. Lancet. 1995; 346(8968):185.

10. Takahashi H, Yoshida K, Sugita T, Higuchi H, Shimizu T. Quetiapine treatment of psychotic symptoms and aggressive behavior in patients with dementia with Lewy bodies: a case series. Prog Neuropsychopharmacol Biol Psychiatry. 2003;27(3):549-553.

11. Lanctôt KL, Herrmann N. Donepezil for behavioural disorders associated with Lewy bodies: a case series. Int J Geriatr Psychiatry. 2000; 15(4):338-345.

12. Marder SR, Mcquade RD, Stock E, et al. Aripiprazole in the treatment of schizophrenia: safety and tolerability in short-term, placebo-controlled trials. Schizophr Res. 2003;61(2-3):123-136.
13. Fernandez HH, Trieschmann ME, Friedman JH. Aripiprazole for druginduced psychosis in Parkinson disease: preliminary experience. Clin Neuropharmacol. 2004;27(1):4-5.

14. De Deyn P, Jeste DV, Swanink R, et al. Aripiprazole for the treatment of psychosis in patients with Alzheimer's disease: a randomized, placebocontrolled study. J Clin Psychopharmacol. 2005;25(5):463-467.

15. Streim JE, Porsteinsson AP, Breder CD, et al. A randomized, doubleblind, placebo-controlled study of aripiprazole for the treatment of psychosis in nursing home patients with Alzheimer disease. Am J Geriatr Psychiatry. 2008;16(7):537-550.

16. Mucci A, Piegari G, Galderisi S. Cognitive-enhancing effects of aripiprazole: a case report. Clin Pract Epidemiol Ment Health. 2008;4(1):24.

17. Kim SW, Shin IS, Kim JM, et al. Effectiveness of switching to aripiprazole from atypical antipsychotics in patients with schizophrenia. Clin Neuropharmacol. 2009;32(5):243-249.

18. Riedel M, Spellmann I, Schennach-Wolff R, et al. Effect of aripiprazole on cognition in the treatment of patients with schizophrenia. Pharmacopsychiatry. 2010;43(2):50-57.

19. Suzuki H, Gen K, Inoue Y. An unblinded comparison of the clinical and cognitive effects of switching from first-generation antipsychotics to aripiprazole, perospirone or olanzapine in patients with chronic schizophrenia. Prog Neuropsychopharmacol Biol Psychiatry. 2011;35(1): 161-168.
Neuropsychiatric Disease and Treatment

\section{Publish your work in this journal}

Neuropsychiatric Disease and Treatment is an international, peerreviewed journal of clinical therapeutics and pharmacology focusing on concise rapid reporting of clinical or pre-clinical studies on a range of neuropsychiatric and neurological disorders. This journa is indexed on PubMed Central, the 'PsycINFO' database and CAS,

\section{Dovepress}

and is the official journal of The International Neuropsychiatric Association (INA). The manuscript management system is completely online and includes a very quick and fair peer-review system, which is all easy to use. Visit http://www.dovepress.com/testimonials.php to read real quotes from published authors. 